\title{
Exploration of Confucianism in "Qianzi Wen"
}

\author{
Xinghe Lei
}

\begin{abstract}
The era of Wei, Jin, Northern and Southern Dynasties was well known in the metaphysics. Has the Confucianism once dominated by social ideology still have an impact in this era? The author believes that Confucianism still has a deeper influence in this era. From the book into the era of Emperor Liangdi of the Southern Dynasties, a good primer "Thousand Characters" can glimpse. As a Mongolian textbook with the longest usage time in ancient China, "Qianwen" has been circulating in China for over 1500 years and has a wide spread and profound influence. Its content involves astronomy, geography, nature, history, figures allusions, the rules and regulations system. And the thought is profound and profound, the author thinks that the content mainly includes the Confucianism ethics moral thought and the Confucian politics thought, has the high thought culture value. The article will take the Confucianism as the starting point and discuss its value from the ideological and cultural aspects.
\end{abstract}

Index Terms-Metaphysics, thousand words, Confucianism, thought.

\section{INTRODUCTION}

"Thousand-word" in terms of content or from the ideological and cultural has many elite worth learning, with the value available for mining. Zhou Xingsi, editor of the Beggar, was the assistant minister of the Liang Dynasty. He gave his life to the upper class of society and had a profound experience of society. He composed only a thousand non-repetitive words into a structured, thoughtful, easy-to-read, easy-to-read article. It appears in the upper strata of the Wei and Jin Dynasties in which the ancient Chinese metaphysics dominated the side culture of the ruling class at that time. Based on the research results of the predecessors, the author puts it in the background of the times and the current ideological and cultural background focuses on the ideological and cultural aspects of the "Thousand-Character Chinese" and attempts to discuss its Confucianism.

\section{THE "ThOusAnd WORDS" CONTENT}

"Thousand-word text" content-rich, all-encompassing. However, due to the age-old content is not easy to understand, is based on the Qing Wang Xiaoyin, Sun Qianyi's argument, "Thousand Character Chinese" to make a general introduction. The "thousand words" divided by Wang Xiao Yin Dici and Sun Qianyi into "four thousand words" are divided into four parts, which they call the four

Manuscript received January 9, 2018; revised April 9, 2018.

Xinghe Lei is with Institute of History and Geography, Longdong University, China (e-mail: leixinghe@126.com). chapters [1].

The first part of the "1000-word" begins with the first sentence of "Heaven and Earth Xuan Huang" to the 36th sentence of "Lai and Wafang", starting from the world. Both talk about the world clouds, sun and moon stars, and four o'clock changes in winter and summer; also talked about all things, rivers and lakes, and birds' flying fish; and involves the transition between man and the world.

The second part of the "thousand words" begins with the 37th sentence "cover this body hair", to the 102nd sentence "Good Lord Ziqi", focuses on the human cultivation standards and principles. The article elaborates on the demeanor, filial piety and man's demeanor, making friends and so on. They pointed out that people should be filial ones and cherish the body that parents pass on. "Christine is Ju Yang, does he dare not to hurt", and people should "know what must be changed" and be honest with others and maintain a true image and credibility. "Couriers can cover this is the meaning of the following four sentences.

The third part of the "Thousand-Character Text" starts with the 103rd "Duyi Huaxia" to the 162nd sentence "Yan Xiuyao Ming" and tells all aspects related to the rule. This chapter begins with a great effort to depict the magnificence of the metropolis and the shape of the capital. For example, "The Palace Pan Yu and the Building Guan Feixue"; secondly, through the description of both the graveyard and the cluster, This is the second meaning of this part, depicting the luxurious life of the upper class and their martial arts. The third meaning of this part describes the vast territory of the country and the beauty of the scenery: "Yu, Kyushu, Kuangyongmian 㝸, rock Xiu 查 Ming."

The fourth part of the "Thousand Words" starts from the first sentence of the 163rd sentence of "treating the peasants in agriculture" to the 248th sentence of "fools and waitresses," mainly describing leisure and tranquil pastoral life, praising those who are willing to loneliness and not fame and fortune, Warmth of the people of the longing for the people. Such as "indulgence, silence loneliness ....." is the description of the music of the hermit.

In the end, there are two sentences of "predicate helpers, which are almost empty" and have no special meaning to be singled out.

\section{The "ThousAnd CHARACTER" IDEOLOGICAL AND CULTURAL-CONFUCIANISM}

Zhou Xingsi is a talented, well-informed and knowledgeable journalist who has carefully arranged only a thousand non-repetitive words into a single book that contains astronomy, geography, nature, history, character allusions, codes of conduct, morality and ethics as well as Confucianism Of the article, and only one thousand words in the article to think seriously, but also put forward his opinion 
of governance. Thousands of words are full of desire for the governance of the world, filled with the warmth of the human yearning, but also revealed the reflection of life, the world, the universe. The following will be Confucian ethics and moral thought, Confucian political rule, Confucian outlook on life in three aspects of its discussion.

\section{A. "Thousand Character" of Confucian Ethics and Moral Thought}

\section{a) Emphasis on moral education}

Our country is a country with a long history and excellent cultural traditions, and is renowned for its ceremonial state. In our traditional culture, traditional moral education occupies a very important position. The ancient rulers and educators all regarded moral education as the most important part of the education of Mongolian students. Ancient moral education has also been the core of the whole education, which runs through all kinds of educational contents. However, as the carrier of ancient Mongolian teaching materials, the above characteristics are more obvious [2]. Although the "Thousand-Character Chinese" was born in the Wei, Jin and Southern and Northern Dynasties prevalent in Metaphysics, its content of moral education still takes Confucianism as the core.

Since spring and autumn, Confucius private learning and teaching content contained in the Analects of Confucius. Confucius's education is mainly composed of four aspects: "writing", "loyalty" and "faith" [3]. In his moral education, he insisted on "being determined to have constant", "introspective", "Practice". Emphasis on ambition, self-control; stressed that the current performance, words and deeds. The teacher educates students based on literature, conduct, loyalty and faithfulness. Obviously, loyalty and faithfulness are the requirements of moral education.

In the four parts of "Thousand Words", each part contains the content of Confucianism. Moral education itself is the core content of Confucian education thought, and moral education is the main melody to be embodied from beginning to end. It is determined by the nature of feudal society and the education of our country. Such as: "Le Ching noble cheap, courtesy and respect; on the next $\mathrm{Mu}$, husband and wife with the Fu; Fu Fu, into the mother instrument; Zhu uncle, more than child; Kong Huai brothers, with gas Lianzhi; friends vote Points, cut mill rules." Talking about the principle and etiquette to be followed between relatives and friends.

The ancients also pay attention to the superiority and inferiority, their parents' respect, and the husband and wife. Although there is some feudal ethics in them, among them, the elders of the elders, XiaoJingda and other Confucianism concepts should be obeyed today. Respect, filial piety is the basic road and obligation of children. Expanding to the whole family, the filial piety of the elders and the caress to the younger generation should be done like inborn ones. This is a kind of fraternity and one of the most adored virtues of ancient Confucius and Mencius. Mencius said: "Lao $\mathrm{Wu}$ and the old man, young $\mathrm{Wu}$ young and young people." Is it to promote Confucianism such a broad love?

The above contents all embody the Confucian doctrine and thought, such examples in the "thousands of characters" more, no longer enumerated.

\section{b) Personal moral standards}

Zhou Xingsi living in the upper class society, but also a literary talent, in his bones there must be a lot of personal moral standards, therefore, in the "thousand words" he talked about the issue of personal morality more, the personal moral standards Summed up as "five permanent", which is Confucianism "benevolence, righteousness, courtesy, wisdom, faith." Under this premise, Zhou Xingsi conducted a wide-ranging and in-depth discussion on the moral cultivation of individuals in the material and spiritual life of the society. This is mainly in the second part. Including: Father, Curtain, change, and talk, friends, read Yin, Liu Fang, temperament, filial piety, and so on.

First of all, we must point out that people want filial piety because, from ancient times to the present, people always think that filial piety is the most important for filial piety, cherish the body that parents pass on to them, and that "complimenting Ju Yang and daring to do harm" means this.

Second, it is pointed out that people should "know the necessity of reform", stress credibility, maintain the true nature and establish a good image and reputation. "The messenger can be deluded, $\mathrm{K}$ read as a holy; German built under the name of the shape of the table is.” That's what it means.

Third, ask people to achieve their own behavior standards. Such as "prolonged play market, eyeballs boxes; easy to brave, is ear wall; with meal, palatability and intestines; The article uses Wang Chong to go to the market to read the examples to illustrate that people who read books, reading is naturally his greatest hobby and interest, so the eyes where the park is naturally where the books are.

In summary, Zhou Xingsi in the "1000 characters" personal cultivation guidelines is also based on Confucianism as the core.

\section{c) Virtuous ethics}

It is arguable that Xian Xing doctrine is one of the key contents of the ethics of Confucian ethics in the "Thousand-Character Chinese Literary Writing". It can be said that Zhou Xingsi's Confucian ethical code runs through a very important part of the ideological content of ", He discusses a wider range, in a nutshell, the following two aspects [4].

The first is the "Five Regularities." In his article, Zhou Hsing-Si said many times that in his opinion the most basic standard of true sage's character is benevolence, righteousness, ritual, wisdom, and faith. It includes behaviors that interact with different kinds of people Guidelines, it should be done. Such as: "benevolent seclusion, making time flies; righteousness set back, Britain Zaiyi bandits loss; sexual quiet Yi, heart and brain fatigue; Talking about the moral virtues of Confucian self-cultivation and moral issues.

Followed by Jiande Li Ming, Confucianism in China, the emphasis is on people's past lives, life to the world, meritorious service, and legislation [5]. Such as: "King line of Wei Yin, Kham read as holy; German name of the establishment, the shape of the table is tabled; empty valley sound, virtual church to listen." The meaning is that people should be the name of Jiande as the goal. The content of life training is very rich, in addition to the basic quality; people also have a higher spiritual pursuit.

Therefore, the ancient sages who have become their idols 
and role models, their usual words and deeds are the instruments of saints, their inner self-restraint is more restrained, this heart and appearance of the realm of repair is that every desire to repair The resulting person longs for it. Therefore, this also reflects Confucianism.

Obviously, the ethical code of ethics we are from Zhou Xing Si is also based on Confucianism.

\section{B. "A Thousand Words" of the Political Rule of the Country}

\section{a) Dehua love people}

Zhou Xingsi in the "thousand words" reflects an important idea that is Germany, love people thinking [6]. This idea stems mainly from Confucian "benevolent government", "rule of law" concept. Rule by morality is the Confucian basic idea and political idea. The so-called rule of virtue is to oppose the harsh martial law, requiring the rulers to use the feudal ethics and morality to ideologically implement the rule of the people, and to govern the country with the method of education and humane policies [7].

In a nutshell, Zhou Xingji's Dehua thought mainly includes Dehua and Aimin, requiring the ruler to subtract the long-term sentence and "hang the people to cut the crime", which is reflected in the sentence of "what compliance law, the Han-shang annoying punishment". Such as: "love to love Lebanon, Minister Fu Rong Qiang; far and near, led by guests; Ming Feng in bamboo, white horse food; is vegetation, Lai and Wanfang." The main thing about the merit week, He loved the nations and loved all nations, so that the world would surrender to all nations, and the brutal ethnic minorities such as Rong and Qiang in the surrounding areas all belonged to the Shun dynasty. The Western Zhou Dynasty was the most desirable time for pre-Qin Confucianism. However, some systems in the Western Zhou dynasty were not implemented at the time, while others were some imaginative contents of the Confucian scholars during the Warring States Period. Therefore, here we can understand these good words and deeds as a desire and longing for good character and the fictional social system as a pursuit of the ideal society.

\section{b) Yin Yin Renneng}

Zhou Xing Si that the king to promote the rule of virtue and be able to govern the world, the key is to enable the wise. This is mainly discussed in the third part. Such as: "Tuanxi Yi Yin, Zuo Shixian; Qufu home, Fu Dan Dilian camp; Huan public Kuanghe, Jiweidouzhuan; Qi Hui Han Hui, said Wu sense of feeling. Speaking is the Magi for the country effectiveness, counsel for the country, the country was rich and quiet.

In ancient times, government officials and loyalists were often able to "worry and worry about the world, and enjoy the music in the world," "Responsible for the people of the world, work hard for the rise and fall of the country. This is the ideal of Confucian scholars in ancient China. It is also the responsibility of a generation of officials. Taking the world as its own responsibility, it shows loyalty to the government and spares no efforts in making the country prosperous. It is a loyal expression of personal perfection in character. Not for personal gain, but only for the common people in the world, this personality is based on a good moral character only. Therefore, their heroic deeds are remembered by their descendants, and their pursuit of life becomes the best example of follow-up to Confucianism [8].

\section{C. "A Thousand Words" View of Life}

We usually talk about the outlook on life, including moral values in life, values and other aspects of life. The outlook on life as reflected in the "Thousand-Character Chinese", that is, its traditional Chinese cultural spirit, mainly includes the following three aspects [9]: Humanism, self-improvement fighting spirit and awareness of moral cultivation. Much has been said about morality and self-cultivation. Here we are only analyzing the spirit of humanism and the fighting spirit of self-improvement.

The first is the humanistic spirit [9]. The Chinese sages argue that in the process of the occurrence and development of all things in the universe, man has a high status in nature. The existence of man and his existence have the universal significance and value that cannot be compared and replaced by others. Confucianism holds the view that "Heaven is humanity and God knows more people." Whether it is Confucius or Mencius kindness theory, or Xunzi's theory of sexuality and evil, the center of knowledge are all human beings.

This kind of people-oriented spirit is reflected in many places in the "one thousand words". The second part of the "thousand words" focuses on the standards and principles of human cultivation, that is, self-cultivation. This emphasizes the role of man, so also reflects the human spirit.

Followed by the fighting spirit of self-improvement, "Book of Changes," said: "Tian Xingjian, the gentleman to self-improvement [9]." This is a concentrated summary of the healthy and self-improvement of the Chinese nation, a concentrated portrait and true portrayal. This spirit of self-improvement in Chinese traditional culture is an excellent tradition of Chinese culture and one of the major elements of Confucianism.

This Great Spirit analyzes the importance of human beings in historical development in the first verse of "Thousand-character Chinese Scriptures" on the basis of heaven and earth and traces the history with the spirit of pioneering spirit. Only the existence of this spirit, as well as its transmission from generation to generation, has promoted the development of Chinese history. It represents the integrity and sentiment of the Chinese nation and can be used as reference today [3].

\section{The Dialectical Succession "ThOusAnd CHARACTER" THOUGHT}

In short, as discussed above, there are many excellent achievements worth learning and inheriting from "Qianwen". Many ideas and contents deserve our reference, especially the essence of Confucianism. This is also the point of discussion in this article. However, we must treat dialectically. Some concepts in the traditional Confucian culture have their historical limitations. Therefore, we should adopt a dialectical succession toward this Enlightenment and adopt a submissive attitude towards it. In the specific reference process also need to pay attention to many issues [10].

First of all, the moral education should be viewed 
dialectically. Fundamentally speaking, "a thousand words" was born in the feudal society and the ideology of the upper class. The ancients in ancient China always regarded the three basic principles and the five permanent principles advocated by Confucianism and feudal ethics as the standard to evaluate morality. Wen "has been reflected. Today, this part has to be abandoned.

We should see that there are many places worthy of our study on the moral education of the "1000-character language". However, we should also see that there are still many historical limitations, such as the way of monarchs, the spouses and so on Out of the limitations of the ideas of the ancients in ancient China, there are many omissions of human nature and disrespect for human nature. The revelation to us is that in our lives, we must respect people, respect human nature, and take people as the foundation [11].

Second, the traditional Confucian culture should be analyzed dialectically. The traditional Confucian culture and education have always been an important part of ancient Chinese education. The Chinese ideology and culture are profound and profound. There are indeed many places worth our pride. However, in the traditional culture, the "1000-character Chinese characters" paid more attention to the great achievements of feudal society in ancient China and the martial arts of the feudal emperors without paying too much attention to the mass class in the society at that time. This should be an improper place, but we must not force the ancients with today's awareness, perhaps because of space.

To sum up, "Thousand-character Chinese" everywhere reflects and promotes the Confucian cultural thought. It is a very ideological and cultural work worthy of our study and inheritance, but also flexible learning, dialectical thinking.

\section{REFERENCES}

[1] X. Y. Wang and Q. Y. Sun, Sentences, Changsha: Yuelu Shu Club, 1987, no. 5, pp. 7-9.

[2] Y. Zhang, "Ancient China Tongren develop education in moral education," Jinyang, no. 1, p. 107, 2004.

[3] Y. Yang. "Confucius education thinking left us thinking," Education Exploration, vol. 5, no. 19, pp. 18-20, 1996.

[4] S. Tan, "A typical model of Chinese character enlightenment education-A review of the historical value and modern usability of 'Qianzi Wen'," Liaoning Teachers' College, no. 1, pp. 79-81, 2000.

[5] P. Hong, "'Thousands of words' trivial," Journal of Shanghai Normal University (Philosophy and Social Science Edition), no. 2, p. 74, 1981.

[6] W. Lu, "The advent of 'Mengzi Wen', an early learning material in China, and its influence on later generations," New Century Libraries, no. 5, pp. 65-66, 2007.

[7] L. Wang, "Chinese traditional Mongolian teaching ideas and their modern value," Jilin Education Science (General Education Edition), no. 5, pp. 8-11, 2001.

[8] L. Wang, "Studying the script 'A thousand words' examination,” Tang Journal, no. 3, 2005.

[9] J. Yan and J. Zhong, "On ancient Chinese teaching material in the traditional culture of the spirit of," Liaoning Education Research, no. 7, pp. 81-82, 2005.

[10] Z. Xu, "Spread thousands of characters and its impact," Chinese Books and Culture, no. 2, pp. 78-79, 1998.

[11] X. Dong, "'Thousand Character' teaching material pattern and the change of teaching consciousness," Master's degree thesis, Jilin University, vol. 35, p. 70, 2007.

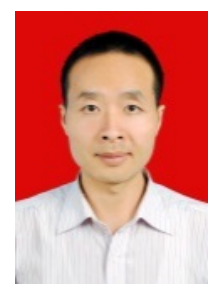

Lei Xinghe was born in February 1985, a master of history and lecturer, in HuanXian county, GanSu province. I won the honorary titles of "national scholarship" and "academic star" during my postgraduate study at northwest normal university. In September 2013, I entered the school of history and geography of LongDong college, and undertook the teaching and research work of "Chinese social history". At present, 10 papers have been published in the journal of Chinese history research, journal of xi 'an petroleum university, journal of LongDong college, etc. It is accepted as a member of the history society of GanSu province and honorary President of Qin Zhidao research institute. 